\title{
BIOÉTICA: ANÁLISE DA CONTRIBUIÇÃO DA EDUCAÇÃO NA CONSTRUÇÃO DAS OPINIÕES DOS ALUNOS DE NÍVEL MÉDIO DE JUSSARA - GO
}

Cálita Pollyanna MARQUES ${ }^{1}$

Aroldo Vieira de MORAES FILHO²

\author{
${ }^{1}$ Licenciatura Plena em Ciências Biológicas, Professor Rede Estadual, calitamarques@ hotmail.com \\ ${ }^{2}$ Licenciatura Plena em Ciências Biológicas, Mestre em Biologia, ETAEB/UFG moraesfilho18a@hotmail.com
}

Recebido em: 06/08/2015 - Aprovado em: 05/01/2016 - Disponibilizado em: 30/07/2016

\begin{abstract}
RESUMO: Com o objetivo de comparar opinião de estudantes do Ensino Médio a respeito de temas que envolvem a Bioética foram aplicados 71 questionários auto-preenchíveis. Participaram quatro turmas, duas de Instituição Privada que cursaram o conteúdo de genética e participaram da aula expositiva ministrada pelo pesquisador e duas de Instituição Pública estando em situação adversa. O objetivo dessa metodologia foi analisar se o conhecimento proporcionado pela orientação da educação influencia nas opiniões dos participantes. Observou-se que as opiniões dos respondentes divergiram, os que cursaram o conteúdo de genética tenderam a concordar totalmente ou parcialmente com as pesquisas cientificas propostas nas situações hipotéticas, porém, alunos que não tiveram a disciplina de genética tenderam a discordar ou concordar parcialmente. Além disso, os participantes demonstraram interesse em adquirir conhecimento sobre os assuntos abordados no questionário. Os resultados reforçaram tanto a importância da educação na construção de opiniões conscientes dos alunos do Ensino Médio, quanto a importância da realização de trabalhos como esse para despertar o interesse pelos temas ligados a Bioética.
\end{abstract}

Palavras-chave: Engenharia Genética. Educação. Análise de Opiniões.

\section{BIOETHICS: ANALYSIS OF CONTRIBUTION EDUCATION IN CONSTRUCTION OF THE OPINIONS OF} HIGH SCHOOL STUDENTS FROM JUSSARA - GO

\begin{abstract}
In order to compare opinion of high school students to respect issues involving bioethics were applied 71 self-administered questionnaires. Participated students from four classes, two private institution who attended the genetic content and attended the lecture given by the researcher and two public institution being in adverse situation. The purpose of this methodology was to analyze the knowledge provided by the orientation of education would influence the opinions of the participants. It was observed that the opinions of respondents diverged, those who attended the genetic content tended to agree fully or partially with the proposed scientific research in hypothetical situations, however, students who have not had the discipline of genetics tended to disagree or partially agree. In addition, participants expressed interest in acquiring knowledge of the issues addressed in the questionnaire. The results contribute to both the importance of education in building conscious opinions of high school students, as the importance of undertaking work like this to awaken interest in issues related to bioethics.
\end{abstract}

Keywords: Genetic Engineering. Education. Analyzing opinions.

\section{INTRODUÇÃO}

Os avanços na Ciência, especialmente na área da Engenharia Genética, têm levantado questionamentos da humanidade perante novas descobertas relacionadas à área. Temas como transgenia, clonagem, manipulação genética, entre outros, exigem reflexões de questões por vezes, moralistas. Nesse campo, surgem as desigualdades no acesso à informação refletido na forma de expressar quando é exigido algum posicionamento do indivíduo, (PEREIRA; 
Pesquisas realizadas por Darwin, Mendel, e outros, constituem um marco do meio científico. No ano de 1944, Oswald Avery, McLead e McCarty descobriram a existência do Ácido Desoxirribonucleico (DNA), a substância que contém o material genético responsável por comandar a síntese protéica do organismo. Em 1953, James Watson e Fracis Crick, por meio da revista Nature, anunciaram a estrutura helicoidal dupla do DNA e, assim, nascia à biologia molecular (BARTH, 2005;JOSEN, 2000).

Alguns anos depois, em 1973, a Engenharia Genética foi introduzida por Cohen e H. Boyerna Califórnia, sendo anunciada a capacidade de recombinação do DNA, sua cadeia poderia ser clivada e colada. Em 2000,com o Projeto Genoma Humano, foi descoberto a composição doDNA da espécie.Nos últimos anos, pesquisas em genética resultaram em três grandes conquistas: a clonagem, o Projeto Genoma Humano e a criação dos transgênicos(BARTH, 2005). As discussões em Bioética, a partir disso, ganharam força pelas possibilidades de pesquisas em seres humanos (CARAMICO; ZAHER; ROSITO, 2007).

Segundo Goldim (2006), o termo Bioética foi introduzido inicialmente por Fritz Jahr em 1927. No entanto, Cloted (2003)e Vital-Santos (2007), afirmam que seu criador foi Van Rensslair Potter em sua obra intitulada Bhioethic: Bridge to the future
(Bioética: uma ponte para o futuro), de 1971. Com a finalidade que atualmenteconhecemos relacionado à medicina e a biologia, foi introduzido por André Helleger, fundador do Instituto Kennedy, da Universidade de Georgetown. A Bioéticaficouligadaaonome do Institutodenominado de The Joseph and Rose Kennedy Institute for the Study of Human Reproduction and Bioethics (CLOTED, 2003; VITAL-SANTOS, 2007).

Segundo Casagrande (2010), Bioética possui grande potencial pedagógico, por despertar interesse, curiosidade e estar diretamente relacionada a diversas áreas de conhecimento. Para mediar à construção da consciência crítica em Bioética surge à educação, que por meio de leituras e discussões direcionadas, proporciona bases ao indivíduo para exporopiniões sobre o tema (CARVALHO; OLYMPIO; ALLAIN,2012; HOSSNE; HOSSNE, 2006).

Como a Bioética está relacionada a temas complexos, é extremamente importante que profissionais da educação auxiliem na construção dessa consciência (CARNEIRO, et al., 2010). O domínio desse conhecimento auxilia na construção de indivíduos capazes de exercer seu papel como cidadão consciente na sociedade (CLOTED, 2003; BOCATTO, 2007).

De acordo com a Lei 9394/1996, que estabelece as Diretrizes e Bases da Educação Nacional (LDBEN), tem como uma de suas prioridades para o Ensino Médio o 
aprimoramento do educando, de modo que haja formação ética e o desenvolvimento da autonomia intelectual e o pensamento crítico (BRASIL, 1996). Um ser crítico, para que não seja influenciado pelas suas crenças e valores pessoais que foram adquiridos e construídos por meio de sua cultura, precisa ter acesso à informação, leitura e discussão de bons referenciais teóricos (FARIA et al., 2014; BARTH, 2005).

Desta maneira, a educação influencia diretamente na forma de expressar opiniões ou tomar decisões diante de temas polêmicos, que envolvam os avanços genéticos.Ao saírem do Ensino Médio, os alunos serão cidadãos com consciência de sua influência perante a sociedade, ou seja, reconhecerão seu papel diante de discussões que abrangem temas polêmicos e conflituosos ligados a descobertas ou novos experimentos científicos (CARVALHO; OLYMPIO; ALLAIN, 2012).

Portanto, a partir desses pressupostos teóricos, objetivou-se avaliar a capacidade da educação em mediar à construção de opiniões de alunos de Nível Médio de Jussara - GO, no que se refere à consciência sobre temas relacionados aos avanços da Engenharia Genética, e assim, ressaltar a importância de sua atuação como construtora da reflexão crítica frente a temas polêmicos, além de descrever e comparar opiniões sobre assuntos relacionados à bioética, de alunos de nível médio com e sem aula expositiva sobre o assunto.

\section{MATERIAIS E METODOLOGIA}

A aplicação de questionários com perguntas que levem o aluno a refletir sobre o tema para expressar opinião, é uma metodologia usada para investigar a contribuição da aprendizagem. Assim, para destacar a relevante importância que a educação tem na formação de indivíduos para exercerem seu papel, seja individual ou coletivo, de forma consciente, o questionário aplicado para comparar as opiniões foi direcionado a turmas de alunos de uma instituição de ensino pública e outra privadado Ensino Médio.

Conforme sugerido por Faerstein et al., (1999),foi adotado questionário autopreenchível para verificar opiniões. Esse método vem se intensificando por diversas características, dentre elas podem-se citar o fato dessa metodologia contar com aplicadores treinados (pesquisadores), baixo custo, padronização do ambiente para preenchimento e estratégias que visem auxiliar o respondente, além de aumentar as taxas de participação, o que confere mais confiança aos dados obtidos.

Previamente, foi realizada uma visita às instituições de ensino objetivando separar as turmas que não tinham acesso aos temas do questionário daquelas que já tinham. Depois dessa verificação, os alunos participantes 
foram esclarecidos sobre a metodologia do trabalho e receberam seus termos de consentimento para os responsáveis preencherem e assinarem. No total participaram quatro turmas, duas da instituição pública e duas da privada.

As turmas de alunos escolhidas para responder o questionário sem que houvesse intervenção da educação, são todos da instituição de ensino pública, cursando o primeiro ano do Ensino Médio. Conforme a grade curricular fornecida pela instituição, os alunos ainda não tinham nenhum acesso aos conteúdos relacionados aos avanços em biogenética, sendo suas opiniões baseadas no senso comum.

Para a instituição de ensino privada foi escolhida turmas que já tinham tido contato direcionado pela educação com os temas que foram abordados no questionário e assim, suas opiniões seriam baseadas no senso cientifico. Apesar dos alunos já terem contato com os temas que seriam abordados, essa instituição foi escolhida para ser feita uma intervenção pelo próprio pesquisador, onde foram usadas duas aulas com duração de 50 minutos cada. Os respondentes que tiveram a aula expositiva do pesquisador são caracterizados por estarem no segundo e terceiro ano do Ensino Médio.

Para montagem das aulas, foi feito um levantamento bibliográfico baseado nos temas abordados no questionário. A aula expositiva realizada foi de acordo com o plano de aula em apêndice. Os temas abordados na aula foram pesquisas com células tronco embrionárias, manipulação genética para escolha do gênero e de algumas características, como ausência de algumas doenças genéticas, clonagem terapêutica, observação e seleção genética de embriões, técnicas gerais de engenharia genética, mapeamento genético e o processo de transgenia.

O questionário foi dividido em três grandes tópicos, sendo o primeiro nomeado por dados gerais que objetiva investigar informações pessoais sobre o aluno; 0 segundo nomeado de análise pessoal sobre o conteúdo, objetivando fazer um levantamento inicial sobre opiniões a respeito do tema e o terceiro com situações hipotéticas baseadas em questões éticas, com finalidade de despertar nos alunos a criticidade sobre diversas situações em bioética.Os questionários antes de serem aplicados foram lidos, de modo que, facilitasse a compreensão do público alvo e depois foram aplicados aleatoriamente pelo pesquisador. Os dados obtidos estão discriminados em gráficos e tabelas com a intenção de facilitar a visualização e a leitura.

Os modelos do questionário, Termo de Consentimento Livre e Esclarecido (TCLE), autorização do responsável pelas Instituições de Ensino e o plano de aula para aula expositiva realizada pelo pesquisador estão em apêndice A, B, C e D respectivamente. 


\section{RESULTADOS}

Foram aplicados 71 questionários, dos quais participaram como respondentes voluntários, alunos de quatro turmas, sendo duas da Instituição de Ensino Pública (sem aula expositiva) e duas da Privada (com aula expositiva). Destes, 32 (45\%) são da Instituição Pública e 39 (55\%) da Privada. Houve uma participação inferior à esperada na Instituição Pública, devido grande parte dos alunos terem esquecido de entregar aos pais o Termo de Consentimento Livre e Esclarecido (TCLE), que autorizava a participação dos menores de 18 anos.

$\mathrm{Na}$ Instituição de Ensino Privada todos os entrevistados declararam ter cursado a disciplina de genética antes da aula expositiva feita pelo pesquisador e a idade média variou entre 15 e 24anos. Enquanto na Pública todos disseram não terem cursado a disciplina, além disso, não tiveram a aula expositiva do pesquisador. A idade dos participantes variou de 13 a 16 anos. Em relação à religião, na Instituição de Ensino Pública, maior número de alunos que se declararam católicos e protestantes em relação à Privada foi observado. Porem, na Privada observou-se um crescimento na diversidade religiosa, com um numero significativamente maior declarando não possuir definição religiosa, 5\% ateu e 5\% espírita, conforme Gráfico 1.

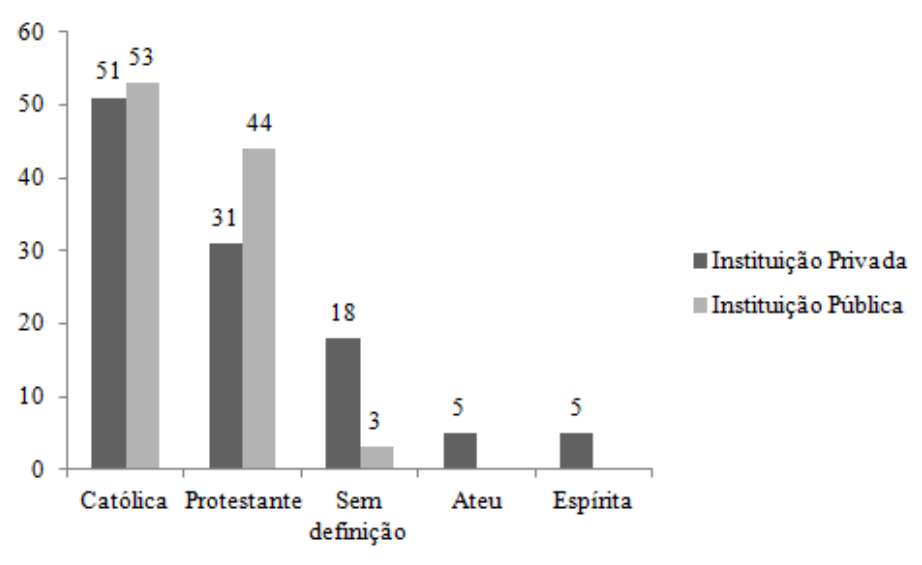

Gráfico 1 - Religião dos alunos da Instituição Pública e Privada em porcentagem $(\%)$

Quando questionados sobre qual melhor metodologia utilizada pelos profissionais da educação para abordar e expor os conteúdos relacionados à Bioética, $10 \%$ afirmaram que o método prático é melhor para a aprendizagem, 14\% acreditam ser melhor o método teórico, com leituras de referenciais bibliográficos e aulas expositivas participativas, nesse caso, ficando restrita ao ambiente da sala de aula. No entanto, para $76 \%$ dos participantes prático e teórico utilizados simultaneamente, geram melhores resultados na criação da consciência crítica em relação aos temas abordados.

No último tópico do questionário, os respondentes analisaram situações hipotéticas baseadas em questões bioéticas. As respostas obtidas, para melhor análise e compreensão, foram separadas respectivamente em instituição pública e privada, sem aula expositiva e com aula expositiva, ficando explícitas as quantidades de participantes em número e porcentagem, conforme Tabela 1. 
Tabela 1 - Respostas das situações hipotéticas das instituições pública e privada

\begin{tabular}{|c|c|c|c|c|}
\hline Perguntas & Sem aula expositiva (Pública) & \multicolumn{3}{|c|}{ Com aula expositiva (Privada) } \\
\hline & $\mathrm{N}^{*}$ & $\%$ & $\mathrm{~N}^{*}$ & $\%$ \\
\hline & 32 & & 39 & \\
\hline \multicolumn{5}{|c|}{ Questão 1: Lei de biossegurança que aprova pesquisas com células-tronco embrionárias } \\
\hline Discordam & 4 & 13 & 1 & 2 \\
\hline Parcialmente & 18 & 56 & 12 & 31 \\
\hline Concordam & 10 & 31 & 26 & 67 \\
\hline \multicolumn{5}{|c|}{ Questão 2: Fertilização in vitro para seleção de gênero da criança } \\
\hline Discordam & 8 & 25 & 8 & 20 \\
\hline Parcialmente & 11 & 34 & 14 & 36 \\
\hline Concordam & 13 & 41 & 17 & 44 \\
\hline
\end{tabular}

Questão 3: Clonagem terapêutica para obtenção de células-tronco embrionárias para tratamento de paraplégicos

$\begin{array}{lcccl}\text { Discordam } & 7 & 22 & 0 & 0 \\ \text { Parcialmente } & 6 & 19 & 15 & 38 \\ \text { Concordam } & 19 & 59 & 24 & 62\end{array}$

Questão 4: Seleção de embriões para exclusão de doenças genéticas ligadas ao cromossomo Y

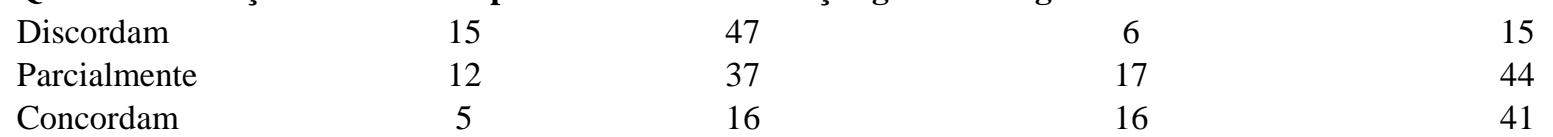

Questão 5: Observação genética para escolha de embriões saudáveis antes da implantação

$\begin{array}{lcccc}\text { Discordam } & 10 & 31 & 4 & 10 \\ \text { Parcialmente } & 18 & 56 & 24 & 62 \\ \text { Concordam } & 4 & 13 & 11 & 28\end{array}$

Questão 6: Manipulação genética e técnicas de fertilização in vitro para excluir características do DNA

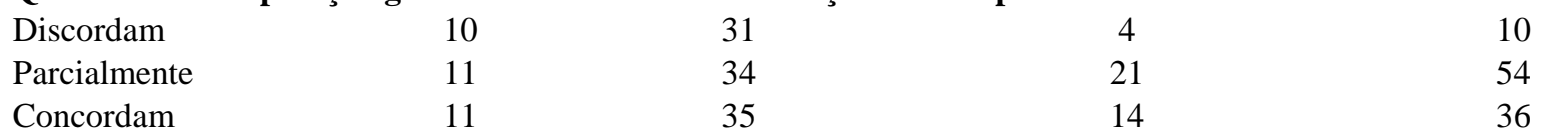

Questão 7: Técnicas de engenharia genética para manipulação de DNA objetivando excluir possibilidade de desenvolvimento de câncer

Discordam

Parcialmente 18

$13 \quad 000$

$\begin{array}{llll}48 & 56 & 19 & 49\end{array}$

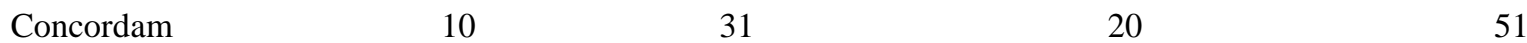

Questão 8: Clonagem e técnica de DNA recombinante para redução dos riscos de rejeição

$\begin{array}{lcccc}\text { Discordam } & 6 & 19 & 1 & 3 \\ \text { Parcialmente } & 10 & 31 & 9 & 23 \\ \text { Concordam } & 16 & 50 & 29 & 74\end{array}$

Questão 9: Mapeamento genético para exclusão no DNA de doenças genéticas

$\begin{array}{lcccc}\text { Discordam } & 7 & 22 & 5 & 13 \\ \text { Parcialmente } & 12 & 37 & 23 & 59 \\ \text { Concordam } & 13 & 41 & 11 & 28\end{array}$

Questão 10: Uso de transgênicos para diminuir problemas, persistentes e emergentes, mundiais relacionados à alimentação

Discordam

Parcialmente 22

Concordam 722

$9 \quad 3 \quad 8$

$69 \quad 23 \quad 59$

$22 \quad 13 \quad 33$

*Número de participantes que assinalaram a alternativa.

\section{DISCUSSÃO}

Discutir Bioética auxilia no processo de formação de cidadãos críticos ao saírem do Ensino Médio, parâmetro proposto pela Lei de Diretrizes e Bases da Educação (BRASIL, 1996). Assim, o ensino de genética, que inclui temas como clonagem, transgenia, tratamento com células-tronco embrionárias, causam 
dúvidas e questionamentos, que conforme sugerido por Cloted (2003), gera necessidade de estudos em Bioética. Os dados dessa pesquisa corroboram com o estudo de Caramico, Zaher e Rosito (2007), em trabalho realizado no curso inicial de medicina observaram que avanços científicos na área da genética abordados em sala de aula levantam dilemas éticos.

Dos entrevistados $76 \%$ optaram pelo método prático e teórico para abordar conteúdos em Bioética, comportamento observado em $95 \%$ dos entrevistados de Lima e Garcia (2011). Para Rosa (2008), e Gonzaga et al., (2012), relacionar teoria e prática é um dos caminhos que resulta em ensino de qualidade, pois os alunos se sentem motivados a participar das aulas propostas, resultando em indivíduos capazes de refletir sobre o mundo e nele agir com autonomia. Diante disso, pela complexidade desses conteúdos, ao serem abordados é necessário o auxilio de aulas práticas e teóricas para melhor aprendizagem (SILVA; MORAIS; CUNHA, 2011).

Houve divergência de opiniões entre alunos que já haviam cursado a disciplina de genética e participado da aula expositiva do pesquisador, daqueles em situação contrária. Ao serem abordados sobre a aprovação de pesquisa com células-tronco embrionárias, $67 \%$ dos alunos com aula expositiva concordam totalmente com o método, enquanto que, $31 \%$ das turmas em situaçãodiferente compartilham opinião. $\mathrm{O}$ assunto causou polêmica e curiosidade, principalmente, em alunos que nunca haviam tido contato direcionado da educação. Segundo Cloted (2003), pesquisas com células embrionárias com o intuito de serem utilizadas em diversos procedimentos, é um tema debatido constantemente e causa divergência de opiniões.

Foi demonstrada consciência ao expor opiniões, em alunos com aula expositiva da Instituição Privada, quando comparado aos da Instituição Pública, que não compartilhavam a mesma situação. Carvalho, Olympio e Allain (2012), em trabalho semelhante realizado com alunos de Ensino Médio, também observaram mudanças de opiniões conforme os temas foram aprofundados por meio de leituras e discussões em sala de aula.

Fornecer base teórica para alunos formarem opiniões de maneira consciente é de extrema importância (CARVALHO; OPYMPIO; ALLAIN, 2012), pois, influencia no comportamento desse indivíduo como futuro cidadão ao exercer seu papel, seja coletivo ou individual (CARAMICO; ZAHER; ROSITO, 2007). De maneira geral, alunos da instituição privada tenderam a concordarem totalmenteou parcialmente com os procedimentos das situações hipotéticas. Comportamento justificado pela base teórica anteriormente fornecida pelo professor de genética da própria instituição e reforçada pelo pesquisador na aula expositiva, durante o 
tempo direcionado a perguntas para sanar dúvidas.

No caso hipotético em que a vítima sofreu lesão na coluna deixando-a paraplégica, a solução proposta foi clonagem terapêutica. Nessa situação, 22\% dos alunos da Instituição Pública discordam totalmente do método, enquanto que nenhum participante da Instituição Privada compartilha a mesma opinião. Para Casagrande (2010), esse método quando realizado em vegetais era considerado normal e aceitável em toda população, situação que mudou com a clonagem da ovelha Dolly. Clonar mamíferos começou a representar a possibilidade de clonagem humana, discussão de cunho ético e jurídico.

Crema (2008), defende que as pesquisas envolvendo qualquer tipo de manipulação genética, ou seja, que interferem na ordem natural do desenvolvimento tem a necessidade do respaldo ético e jurídico. Segundo Cunha (2005), manipulações genéticas geram alterações imprevisíveis na sociedade, mudando a compreensão dos fenômenos sociais e, assim, refletindo em suas atitudes para com seus semelhantes.

Diante disso, Alves e Caldeira (2005), propõem a necessidade de discussões de cunho ético e moral para formação da Bioética. Além disso, as opiniões sobre assuntos que vão além do senso comum, para ganharem força perante discussões, precisam estar alicerçadas em conhecimentos construídos em leituras de material cientifico sobre o tema, sendo necessário o acompanhamento de profissionais da educação que vão orientar e direcionar na formação da consciência do indivíduo (ALVES; CALDEIRA, 2005).

Desta maneira, a presente pesquisa reforçou a importância da educação na construção da consciência cidadã dos alunos do Ensino Médio ao discutirem assuntos referentes aos avanços em biogenética que envolva questões bioéticas. A própria LDB 9394/96, ao propor em seus artigos que esse nível de ensino forme consciência cidadã crítica, destaca a importância da educação. Além disso, mesmo alunos sem base teórica para discutirem sobre o tema, após a realização da pesquisa demonstram crescente interesse pela Bioética, comportamento observado por Hossne e Hossne (2006),que especificamente nesse caso, ressalta a importância do desenvolvimento de trabalhos desse porte.

\section{CONCLUSÃO}

Alunos do Ensino Médio precisam de orientação dos profissionais da educação para expor opiniões sobre questões em bioética de forma sensata. Conclusão respaldada diante da relevante diferença de opiniões entre alunos que haviam tido contato direcionado sobre os avanços genéticos, alunos da Instituição Privada, e alunos que ainda não haviam tido esse mesmo direcionamento, alunos da Instituição Pública. 
O interesse e curiosidade observados nos alunos que nunca haviam tido contato com o tema anteriormente a aplicação do questionário, enfatiza a importância de trabalhos científicos como esse. Assim, é relevante pesquisas cientificas que destaquem a importância do educador na construção de

\section{REFERÊNCIAS}

ALVES, S. B. F.; CALDEIRA, A. M. de A. Biologia e Ética: Um estudo sobre a compreensão e atitudes de alunos de Ensino Médio frente ao tema Genoma/DNA.

Pesquisa em educação e ciências, Belo Horizonte, v. 7, n. 1, p. 1-12, ago. 2005.

BARTH, W. L. Engenharia Genética e Bioética. São Paulo, Revista TRIM, v. 35, n. 149, p. 361-391, 2005.

BOCCATTO, M. A importância da bioética. Genética na Escola. São Paulo, v. 2, n. 2 p. 11-14, 2007.

BRASIL. Ministério da Educação e Cultura. Lei $n$. 9.394, de 23 de dezembro de1996. Fixa as diretrizes e bases da educação nacional. Brasília: Ministério daEducação e Cultura, 1996.

CARAMICO, H. J.; ZAHER, V. L.; MARGARÉTE, M. B. Ensino da Bioética nas Faculdades de Medicina no Brasil. Bioethikos - Centro Universitário São Camilo. v. 1, p. 76-90, 2007.

CARNEIRO, L. A.; PORTO, C. C.; DUARTE, S. B. R.; CHAVEIRO, N.; BARBOSA, M. A. O ensino da ética nos cursos de graduação da área da saúde. Revista brasileira de educação médica, v. 34, n. 3, p. 412-421, 2010. opiniões conscientes, uma vez que, os alunos são futuros cidadãos que exercerão papeis fundamentais na sociedade e, para desempenhar essa função corretamente, precisam estar bem orientados sobre temas que envolvam questões éticas e legais, como avanços científicos na genética.

CARVALHO, A. J. S.; OLYMPIO, N. Z.; ALLAIN, L. R. Bioética para alunos do Ensino Médio. Alfenas: Unifal, 2012.

CASAGRANDE, V. G. Aborto Eugênico. 2010. 95 f. Trabalho de conclusão de curso para a obtenção do título de especialista em preparação para a magistratura Estadual. Universidade do Extremo Sul Catarinense, Criciúma, 2010.

CLOTET, J. Bioética: uma aproximação. Porto Alegre, p. 256, 2003.

CREMA, L. G. A possibilidade ético-jurídica do direito à origem genética na reprodução assistida heteróloga. 2008. 117 f. Trabalho de conclusão de curso (Bacharelado em Direito) - Universidade do Vale do Itajaí, Centro de Ciências Jurídicas e Sociais, São José, 2008.

FAERSTEIN, E.; LOPES, C. de S.; VALENTE, K.; PLÁ, M. A. S.; FERREIRA, M. B. Pré-teste de um questionário autopreenchível: a experiência pró-saúde UERJ. PHYSIS, Revista Saúde Coletiva, Rio de Janeiro, p. 117-130, 1999.

FARIA, J. C. N. de M.; MORAES, M. G. de;STRINI, P. J. S. A.; SABÓIA-MORAES, S. M. T. Fundamentos de Biologia Celular e Tecidual para o Ensino. In: Especialização em Tecnologias Aplicadas ao Ensino de Biologia. Org. Moreira, P. C.Tecnologias Aplicadas ao 
Ensino de Biologia. 3 ed., v. 3, p. 13-106, 2014.

GARRAFA, V.; CORDÓN, J. Pesquisas em Bioética no Brasil de hoje. 10. ed. São Paulo: Editora Gáia, 2008.

GOLDIM, J. R. Bioética: Origens e complexidade. 2. ed. Porto Alegre: HCPA, 2006.

GONZAGA, P. da C.; SANTOS, C. de M. R. dos; SOUSA, F. M. da C. de; COSTA, M. L. da. A prática do ensino de Biologia em escolas públicas: Perspectivas na visão de alunos e professores. 3. ed. Campinas: Junqueira\&Marin Editores, 2012.

HOSSNE, W. S.; HOSSNE, R. S. Opinião do estudante de medicina sobre algumas questões Bioéticas. MundoSaúde, v. 30, n. 4, p. 673677, 2006.

JOSEN, A. R. A short history of medical ethics. New York: Oxford University Press, p. 99-120, 2000.

LIMA, D. B. de; GARCIA, R. N. Uma investigação sobre a importância das aulas práticas de Biologia no Ensino Médio. Cadernos do Aplicação, Porto Alegre, v. 24, n. 1, p. 201-224, jun. 2011.

PEREIRA, T. de L.; SÀNCHEZ, C. A Bioética e o Ensino de Ciências: Algumas reflexões. Ciência em Tela, v. 3, n. 1, 2010.

ROSA, A. M. Relacionar teoria e prática na matemática do Ensino Fundamental e Médio. 2008. 64 f. Trabalho de conclusão de curso (Licenciatura Plena em Matemática) Universidade Estadual de Goiás, Unidade Universitária de Jussara, Jussara, 2008.

SILVA, F. S. S. da; MORAIS, L. J. O.;

CUNHA, I. P. R. Dificuldades dos professores de Biologia em ministrar aulas práticas em escolas públicas e privadas do município de Imperatriz - MA. Revista UNI, Imperatriz, v. 5, n. 1, p. 135-149, jul. 2011.
VITAL-SANTOS, D. Ensino da Bioética em Cursos de Graduação em Enfermagem: Uma Proposta Metodológica. 2007. 134 f. Trabalho de conclusão de curso (Programa de Pósgraduação em saúde coletiva), para obtenção de título de Mestre em saúde coletiva, Feira de Santana, 2007. 